\title{
PROPIEDAD DE LA TIERRA Y ORDENAMIENTO SOCIAL EN LA CASTILLA DEL SIGLO XVI: A PROPOSITO DE LA OBRA DE DAVID E. VASSBERG
}

\author{
ANGEL GARCIA SANZ \\ Universidad de Valladolid
}

De nuevo vuelve D. E. Vassberg (1986) a sorprendernos muy gratamente a los historiadores agrarios de la España moderna con una espléndida obra. Tras su libro, todavía reciente [D. E. Vassberg (1983)], que constituye el estudio más extenso, globalizador y concluyente de los publicados por el momento sobre ese importante tema de las ventas de tierras concejiles por parte de la Hacienda - fue objeto de recensión por parte de Bartolomé Yun (1985 a)-, se publica ahora en castellano, a los dos años de su aparición en inglés, Tierra y Sociedad en Castilla, obra de gran aliento y digna de ser celebrada por varios justos motivos, entre los que voy a subrayar sólo tres.

El primer motivo de celebración es el tema mismo: las relaciones entre propiedad de la tierra y ordenamiento social en la Castilla del siglo xvi. Y es que es de agradecer en el actual momento de la historiografía económica sobre la España moderna, dominada en exceso, creo yo, por la atención a los cambios en la coyuntura económica - variación en la cuantía de la población, fluctuación de la producción agraria, movimiento de la renta, de los precios, de los salarios, etc.-, el plantear investigaciones que aborden aspectos estructurales que, si bien suelen ser de difícil precisión cuantitativa por la naturaleza de las fuentes de información que pueden emplearse, poseen una gran virtualidad explicativa no sólo del comportamiento de las variables económicas, sino también de otras muchas cuestiones que sobrepasan el ámbito estrictamente económico para adentrarse en la comprensión de la sociedad, su organización de poder y la política. Este es, desde luego, el caso del estudio del régimen de la propiedad de la tierra al que dedica Vassberg su libro, obra ésta que, en mi opinión, retoma y vuelve a dar nuevos alientos a una tradición historiográfica -identificable por sus métodos y por la índole de la problemática objeto de sus investigaciones- cuyos principales epígonos serían Carmelo Viñas y Mey, Ramón Carande, Noël Salomón y Felipe Ruiz Martín. Junto a ellos habría que mencionar a Alejandro Nieto, que tan relevantes contribuciones ha hecho al tema desde el campo de la historia del Derecho y de las instituciones. 
El segundo gran mérito de este libro es subrayar - tres de los siete capítulos se dedican a ello- un aspecto de la historia rural castellana poco tratado, si no olvidado del todo: la importancia y funcionalidad -económica, social, fiscal- de la propiedad territorial comunal que se concreta en bienes sometidos a diferentes regímenes jurídicos, a diversas prácticas de aprovechamiento - baldíos, comunes, propios, etc.-, pero cuya existencia pone de manifiesto la pervivencia en el siglo xvi - y en los otros siglos modernosde lo que Vassberg designa como «tradición comunitaria». $Y$, junto a los bienes comunales, el autor no olvida los derechos colectivos plasmados en servidumbres de aprovechamiento - en especial «la derrota de las mieses»Tanto bienes como derechos son descritos convincentemente por Vassberg señalando su funcionalidad en la economía agraria, en la sociedad rural a partir de una documentación de primera mano. Estima el autor que el motivo de no haber prestado los historiadores agrarios la debida atención a la cuestión de los bienes y derechos comunales radica en que su existencia y su uso estaban confiados a la costumbre, y lo consuetudinario no precisa ser escrito, sobre todo en una sociedad tradicional, por lo que los testimonios documentales al respecto son escasos. A este motivo habría que añadir la predisposición mental del historiador contemporáneo a razonar sobre la base de la existencia exclusiva de la propiedad territorial burguesa, particular. Sin embargo, pocas cosas hay más urgentes que el que el historiador agrario de las épocas medieval y moderna se resista a ser víctima de esa predisposición. Al igual que ocurre en el campo de la demografía histórica, en el que es necesario superar el análisis de los comportamientos de los individuos insertándolos, para explicarlos adecuadamente, en el estudio más complejo y amplio de la unidad familiar, algo análogo acontece en las investigaciones de historia agraria de aquellas épocas en las que siempre hay que contemplar las explotaciones familiares campesinas en el marco de la comunidad aldeana, cuyos componentes eran titulares colectivos de derechos de propiedad y de aprovechamiento de bienes comunales, y obedecían a la disciplina comunitaria en el laboreo y uso de la tierra -incluso de aquella que les pertenecía en calidad de propiedad privada - por encima del interés particular. En definitiva, las posibles decisiones económicas inspiradas en el logro del beneficio individual se hallaban mediatizadas por toda una serie de prácticas consuetudinarias que respondían al interés comunitario y que solían estar recogidas en las Ordenanzas lugareñas. Sin tener muy presente la existencia y funcionalidad de las tierras baldías y «entradizas», difícilmente se pueden explicar de forma convincente las fases seculares de expansión y depresión - son en especial esas tierras las que periódica y alternativamente entran en cultivo o quedan eriales-. Otro tanto ocurre con los intentos de explicar la capacidad tributaria de los pueblos cuyos vecinos, a los que se obliga a pagar solidariamente cupos repartidos al lugar 
en cuanto tal, cuentan no sólo con sus recursos particulares, sino también con bienes municipales que pueden enajenar —en cuanto a la propiedad o sólo en cuanto al usufructo, cumpliendo o sin cumplir los requisitos legales exigidos- o hipotecar a fin de obtener dinero para satisfacer las exigencias de la Hacienda. La reciente investigación de Bartolomé Yun Casalilla (1985 b) constituye una buena contrastación empírica de lo que voy diciendo.

El tercer mérito que deseo subrayar es haber utilizado como fuente de información una documentación insólita en investigaciones sobre esta temática y que consiguientemente aporta nuevas noticias, desconocidos testimonios. Me refiero en especial a los fondos documentales de los Archivos de las Chancillerías de Valladolid y de Granada - pleitos-y del Archivo General de Simancas, en su sección de Expedientes de Hacienda - las «averiguaciones" de Felipe II-, fondos documentales a los que permanentemente se remite el autor en las notas a pie de página. Si comparamos el apoyo informativo del viejo libro de C. Viñas y Mey (1941) con la base documental de la obra de Vassberg (1986), resulta evidente el gran avance experimentado en lo tocante a la calidad y fiabilidad de las fuentes utilizadas para conocer la historia de la propiedad territorial en la época moderna. De un tratamiento del tema basado fundamentalmente en las «impresiones» de los memoriales y escritos de los arbitristas, y de los testimonios siempre interesados de los procuradores recogidos en las Actas de Cortes, se ha pasado a una investigación que aduce noticias considerablemente más precisas, más variadas, más contrastadas, fehacientes y abundantes extraídas de los pleitos en que se dirimían diferencias sobre la propiedad y uso de la tierra en los pueblos, y de las «averiguaciones» sobre la riqueza mandadas hacer por Felipe II y que se guardan en Simancas. Hay que señalar que, ya hace más de veinte años, Noël Salomón (1964) había utilizado una fuente análoga a las «averiguaciones» a que me refiero: «las relaciones topográficas», que, por lo que sabemos, sólo se ejecutaron en Castilla la Nueva.

Como puede apreciarse por lo que llevo dicho, no es sólo en el estudio de los aspectos coyunturales de la historia agraria en el que se ha experimen. tado un evidente progreso por lo concerniente a la calidad de las fuentes informativas empleadas - diezmos, documentación contable, etc.-; algo similar ha ocurrido con la documentación utilizada para el estudio de la propiedad territorial y las relaciones sociales. $Y$, habida cuenta de la riqueza documental de los archivos españoles para la historia económica y social de la época moderna, es previsible que el progreso en la utilización de fuentes ha de proseguir. El mismo Vassberg afirma en la introducción que deliberadamente ha renunciado a trabajar los archivos municipales a fin de adelantar una visión global y abierta del tema que trata -excluido el territorio gallego, asturiano y vasco-, aunque es consciente de que ese trabajo está pendiente. Yo agre- 
garía que, además, está pendiente el trabajo en los fondos de protocolos notariales, que por lo general se custodian en los archivos históricos provinciales y que tan fértiles han de ser para el conocimiento de la propiedad territorial -apeos, inventarios post mortem de bienes, etc.-, y de las relaciones sociales en el campo - contratos agrarios, censos, etc.- Buen testimonio de lo que afirmo sobre las posibilidades informativas de la documentación notarial es la obra de Antonio Eiras Roel y colaboradores (1981).

Respecto a la estructura de la obra de Vassberg (1986), ésta consta de siete capítulos, que cabe agrupar en dos secciones. Los cinco primeros tratan de un aspecto eminentemente estructural: las características de la propiedad territorial según la naturaleza jurídica y personal de los titulares. Así distingue, en primer lugar, la propiedad colectiva de los pueblos, a la que dedica los tres primeros capítulos, titulados «La tradición comunitaria», «La propiedad municipal» y «Otros aspectos del sistema comunitario» -reúnen 115 páginas los tres capítulos y representan un 40 por 100 del texto, excluida introducción, bibliografía e índices; en segundo lugar trata de la propiedad privada, diferenciando la poseída por los privilegiados —capítulo cuarto-y la perteneciente a los no privilegiados - capítulo quinto-.

Los dos capítulos finales del libro - titulados «Cambios en la producción y en la propiedad de la tierra» y «El creciente malestar rural»- evidencian una perspectiva de análisis más atenta a la dimensión temporal o diacrónica, esto es, a las variaciones que se van experimentando en la economía y sociedad rural castellanas a lo largo del siglo, una perspectiva, en suma, más sensible a lo coyuntural. Así, se trata del progresivo desequilibrio entre superficie cultivada (ager) y superficie de pastizal y monte (saltus y silva) a favor de aquélla, la paulatina sustitución de bueyes por mulas como ganado de labor; se alude, igualmente, a la evolución de la población, de la producción agraria, de la renta, de la presión fiscal, de los precios. También, obviamente, Vassberg subraya aspectos coyunturales que van modificando el régimen de propiedad de la tierra a lo largo de la centuria: la progresiva privatización de la propiedad comunitaria, la concentración territorial creciente, la función que en todo ello desempeña el endeudamiento campesino y las exigencias fiscales. El libro se detiene en el umbral mismo de la crisis castellana del siglo xvir, después de habernos conducido razonablemente hasta él.

Sorprenden en esta obra algunos olvidos bibliográficos, los cuales, de haber podido ser evitados -aspiración de difícil logro cuando el autor ha de trabajar en Universidades extranjeras-, habrían enriquecido el texto, aunque desde luego no habrían alterado su sentido. Tal es el caso de, por ejemplo, el trabajo de Felipe Ruiz Martín (1974), el de Alejandro Nieto (1959), el de José M. Mangas Navas (1981). También considero que le habría sido de alguna utilidad -permítaseme el atrevimiento- el trabajo de A. García Sanz 
(1980), en el que trataba uno de los temas centrales del libro de Vassberg para un territorio bien preciso. Respecto a la utilización de fuentes legislativas, más oportuno habría sido manejar alguna de las ediciones de la Nueva Recopilación - de la aparecida en 1640 existe edición facsímil de Ed. Lex Nova, Valladolid, 1982- en lugar de la Novísima, que recoge sólo las disposiciones que se mantenían vigentes ya en una época tan tardía como los primeros años del siglo xIx. También habría sido de utilidad la consulta del repertorio de disposiciones denominado Ordenamiento de Montalvo, de 1484, sobre todo en su libro séptimo.

D. E. Vassberg $(1986,212)$ atribuye a Gonzalo Anes $(1970,92-97)$ el «enfoque general» aceptado por «la mayoría de los eruditos», según el cual fue importante el impacto de la demanda colonial de productos del campo como factor de la expansión agraria castellana del siglo xvi. Pero es bien sabido que Gonzalo Anes $(1983,193-204)$ sostiene más recientemente y con aportación de razones suficientes que «las exportaciones a Indias no pudieron, por su cuantía, desempeñar otro papel que el de minúsculos impulsos de unas tendencias más complejas». Ya Viñas y Mey subrayó en El problema de la tierra... la función estimulante de la demanda colonial, y su tesis mereció, por excesiva, la atinada crítica de Ramón Carande (1941).

D. E. Vassberg $(1986,201)$ califica a Caxa de Leruela de «acérrimo defensor de la Mesta», lo cual, en el mejor de los casos, merece ser matizado a la vista del contenido de la Restauración en la antigua abundancia de España. Hay que precisar que lo que realmente defiende Caxa en su obra es el fomento de una ganadería integrada en el proceso productivo agrícola y poseída por numerosos pequeños y medianos ganaderos-agricultores —véase sobre esto el trabajo de Jean Le Flem (1975).

Una última observación: en ocasiones no es rigurosa la utilización de los vocablos «propiedad» y «posesión». A veces se emplean como equivalentes en la versión al castellano cuando es bien clara la diferencia de su contenido conceptual. Por ejemplo, en la introducción [Vassberg (1986, 10)] nos encontramos con la siguiente frase: «Este libro trata fundamentalmente de la tierra y de su posesión. Creo que es evidente la importancia de la propiedad de la tierra para la vida del campesinado -el subrayado es mío-. Esta frase podría sugerir en un lector atento y preocupado con la conceptualización precisa que el libro trata de las formas de tenencia de la tierra -y no de la propiedad - y que era importante para los campesinos el dejar de ser poseedores para hacerse propietarios. En ese pasaje, en la edición inglesa se utiliza un mismo vocablo para expresar lo que los traductores vierten como posesión y como propiedad: landownership.

Pero todas estas observaciones son de pequeña monta, como se ve, y en nada pueden empañar los méritos fundamentales de la importante contribu- 
ción que Vassberg hace con su obra al conocimiento de la historia económica y social de la Castilla rural del siglo xvi. El que haya insertado en su trabajo los principales resultados de las investigaciones recientes no es un valor desdeñable y es una razón más para recomendar la lectura de este libro.

\section{BIBLIOGRAFIA}

ANEs, G. (1970): Las crisis agrarias en la España moderna, Madrid, Tecnos.

- (1983): «La agricultura española y el mercado americano», en Historia económica y pensamiento social, Madrid, Alianza, pp. 193-204.

Carande, R. (1941): «Reseña del libro de Viñas y Mey: El problema de la tierra en la España de los siglos XVI y XVII», Escorial, V, pp. 451.461.

EIras RoEL, A., et al. (1981): La bistoria social de Galicia en sus fuentes de protocolos, Santiago de Compostela.

Garcfa SAnz, A. (1980): «Bienes y derechos comunales y el proceso de su privatización en Castilla durante los siglos XVI y xviI: el caso de tierras de Segovia», Hispania, núm. 144, pp. 95-127.

Le FrzM, J. P. (1975): *¿Miguel Caxa de Leruela, defensor de la Mesta?», introducción a la reciente edición de la obra de Caxa de Leruela, Madrid, Instituto de Estudios Fiscales.

Mangas Navas, J. M. (1981): El régimen comunal agrario de los concejos de Castilla, Madrid, Ministerio de Agricultura.

Nreto, A. (1959): Ordenanza de pastos, bierbas y rastrojeras, Valladolid.

Ruiz Martf́, F. (1974): «Pastos y ganaderos en Castilla: La Mesta, 1450-1600», en La lana come materia prima, Firenze, Istituto Internazionale di Storia Economica *Francesco Datiniw, pp. 271.285.

Salomón, N. (1964): La campagne de Nouvelle Castille à la fin du XVI" siécle d'après les «Relaciones Topográficas», París, Ecole Pratique des Hautes Etudes (que se vertió al castellano con el evidente «excesivo» título de La vida rural castellana en tiempos de Felipe II, Barcelona, Ed. Planeta, 1973).

VASSBerg, D. E. (1983): La venta de tierras baldias. El comunitarismo agrario y la Corona de Castilla durante el siglo XVI, Madrid, Ministerio de Agricultura, Pesca y Alimentación.

- (1986): Tierra y Sociedad en Castilla. Señores «poderosos» y campesinos en la España del siglo XVI, Barcelona, Ed. Crítica (331 pp., bibliografía e índice de materias y autores, traducción de José Gutiérrez y Marian Ortuño).

VIÑAs Y MEY, C. (1941): El problema de la tierra en la España de los siglos XVI y XVII, Madrid, CSIC.

Yun Casalilla, B. (1985 a): «Reseña del libro de Vassberg: La venta de tierras baldias", Revista de Historia Económica, núm. 1, pp. 174-177.

- (1985 b): Economía y sociedad en la Tierra de Campos, 1500-1830, tesis de Doctorado inédita leída en la Facultad de Filosofía y Letras de Valladolid. 